\title{
Atuação da defesa civil na avaliação e análise de riscos ambientais
}

\author{
Daris Correia dos Santos' \\ 'Doutoranda em Engenharia Civil, Universidade Federal do Ceará, Fortaleza, Brasil
}

\section{Resumo}

Os procedimentos utilizados na avaliação de risco diferem conforme a natureza do fenômeno abordado, pois a avaliação de risco envolve informações referentes a projetos implantados e suas possíveis consequências. As atividades de análise e setorização de risco dos processos de instabilização das encostas, realizadas em novembro de 2011 a fevereiro de 2012, consistiu em vistorias técnicas para a identificação dos pontos críticos, riscos e vulnerabilidades, auxiliando as ações desenvolvidas pela Defesa Civil e avaliação da realização das obras de caráter preventivo de acordo com os efeitos ambientais potenciais das áreas de riscos e do grau de reversibilidade dos impactos ambientais para os assentamentos urbanos precários denominados bairro Ivaldolândia, Conjunto Vida Nova, Mazagão e Mutirão localizados na região do Município de Alagoa Nova- PB, Brasil. A análise de riscos e impactos ambientais consistiu na delimitação da área de estudo, identificação da tipologia dos processos geodinâmicos, mapeamento de risco e elaboração da matriz de Leopold. Através da análise dos impactos ambientais relevantes nas áreas de risco do município de Alagoa Nova, na Paraíba, é possível adotar medidas mitigadoras e avaliar a importância, magnitude e frequência que tais fatos ocorrem. Verifica-se que a estabilização do solo de encostas com muros de arrimo e o uso de vegetação como também a remoção de pessoas das áreas críticas, minimizam a vulnerabilidade da população. A posição das moradias em relação à inclinação dos taludes gera risco, o que torna imprescindível evitar alterações drásticas da topografia e respeitar os afastamentos mínimos estabelecidos junto às encostas.

Palavras-chave: Riscos. Impactos. Defesa Civil. Setorização. Topografia.

\begin{abstract}
The procedures used in risk assessment differ according to the nature of the phenomenon addressed, because the risk assessment involves information relating to projects implemented and their possible consequences. Analysis activities and sectorization risk of destabilization of slopes processes undertaken in November 2011 and February 2012 surveys consisted of techniques for the identification of critical points, risks and vulnerabilities thus helping the actions taken by the Civil Defense and evaluation of achievement preventive works according to the potential environmental effects of the risk areas and the degree of reversibility of environmental impacts for urban squatter settlements called neighborhood Ivaldolândia, Conjunto Vida Nova, Mazagão and Mutirão located in the Municipality of Alagoa Nova, PB, Brazil. The analysis of environmental risks and impacts involved the delineation of the study area, identifying the type of geodynamic processes, risk mapping and elaboration of the Leopold matrix. Through the analysis of the environmental impacts relevant risk areas of the city of Alagoa Nova Paraíba is possible to adopt mitigation measures and assess the importance, magnitude and frequency that such events occur. It appears that the stabilization of soil slopes and retaining walls using vegetation and the removal of people from critical areas minimize the vulnerability of the population. The position of the housing relative to the inclination of the slope generates risk which makes it imperative to avoid drastic changes in topography and observe the minimum clearances established along the slopes.
\end{abstract}

Keywords: Risks. Impacts. Civil Defense. Sectorization. Topography. 


\section{INTRODUÇÃO}

Entre as atividades desenvolvidas na Defesa Civil estão à identificação dos pontos críticos, com seus riscos e vulnerabilidades; a realização das obras de caráter preventivo conforme os efeitos ambientais potenciais das áreas de riscos; e de acordo com o grau de reversibilidade dos impactos, a remoção da população de áreas críticas.

A ocorrência e a intensidade dos desastres dependem muito do grau de vulnerabilidade dos cenários e das comunidades afetadas do que pela magnitude dos eventos adversos; a partir da constatação de que os desastres podem e devem ser minimizados, cresce a importância da mudança cultural relacionada ao senso de percepção de risco que é diretamente proporcional ao grau de desenvolvimento social de uma determinada comunidade ou grupo populacional, considerado em seus aspectos psicológicos, éticos, culturais, econômicos, tecnológicos e políticos (POLÍTICA NACIONAL DE DEFESA CIVIL, 2007).

O $2^{\circ}$ artigo do Estatuto das Cidades (Lei $\mathrm{N}^{\circ} 10.257$ de 10 de julho de 2001) determina as diretrizes que devem ser seguidas pelo Município ao organizar sua política urbana, todas elas voltadas para garantir cidades justas, em que todos, pobres e ricos, desfrutem dos benefícios da urbanização.

Esse trabalho tem como objetivo a análise e avaliação de impactos nos processos de instabilização de encostas dos conjuntos habitacionais precários denominados bairro Ivaldolândia, Conjunto Vida Nova, Mazagão e Mutirão localizados na região do Município de Alagoa Nova- PB.

A sua estruturação consiste na avaliação de impactos ao meio ambiente, nos procedimentos para o planejamento urbano e análise de riscos, em critérios ambientais adequados e medidas mitigadoras, levando em consideração o descontrole de construções em áreas de risco, como também a falta de infraestrutura do referente município.

De acordo com Silva (1989), EIA é um processo de estudo utilizado para prever as consequências ambientais resultantes do desenvolvimento de um projeto.

A Avaliação de Impacto Ambiental é estabelecida a partir dos Estudos de Impacto Ambiental (EIA). Esses estudos são constituídos de um conjunto de atividades técnicas e científicas que incluem o diagnóstico de ambiência com a característica de identificar, prevenir, medir e interpretar, quando possível, seus impactos.

Pimentel (1992) contribui com essa questão ressaltando que a AIA não é um instrumento de decisão, mas sim de subsídio ao processo de tomada de decisão. Seu propósito é de obter informações através do exame sistemático das atividades do projeto. Isso permite que se possam maximizar os benefícios, considerando os fatores saúde, bem-estar humano e meio ambiente como elementos dinâmicos no estudo para avaliação.

Os impactos ambientais que acontecem em larga escala refletem a implantação de grandes empreendimentos e, em muitos casos, repercute distante dos locais em que foram implantados, gerando impactos nos centros urbanos, que, na verdade, são os destinatários dos insumos provenientes destes mesmos grandes projetos. Os impactos generalizados se sobrepõem aos de natureza ecológica, pois modifica a paisagem, o que pode facilitar a avaliação de tais impactos sobre a qualidade de vida e sobre as próprias estruturas sociais e econômicas das áreas ou regiões em que se encontram (SOUZA, 1999).

Fogliatti (2004) apresenta a concepção de impacto ambiental que afirma que o mesmo é qualquer alteração no sistema ambiental físico, químico, biológico, cultural e socioeconômico que possa ser atribuída às atividades humanas, relativas às alternativas em estudo para satisfazer as necessidades de um projeto.

Um dos métodos mais utilizados na identificação e classificação dos aspectos e impactos ambientais quantificados na Avaliação de Impactos Ambientais (AIA) é a matriz de Leopold que consiste da união de duas listas de verificação. Uma lista de ações ou atividades é mostrada horizontalmente, enquanto uma lista de componentes ambientais aparece verticalmente. A inclusão dessas duas listas de verificação em uma matriz ajuda a identificar os impactos, uma vez que os itens de uma lista podem ser sistematicamente relacionados a todos os outros itens da outra lista, com o objetivo de identificar os possíveis impactos (LEOPOLD et al, 1971).

Segundo Tommasi (1993), o método da matriz de Leopold permite uma rápida identificação, ainda que preliminar, dos problemas ambientais envolvidos num dado projeto. Envolve aspectos físicos, biológicos e socioeconômicos, porém, apresenta desvantagens, como por exemplo, não permite 
avaliar a frequência das interações nem fazer projeções no tempo e apresenta grande subjetividade, sem identificar impactos indiretos nem de segunda ordem.

Moreira (1995) diz que as matrizes são utilizadas na identificação dos impactos ambientais diretos e cita como vantagens das mesmas:

1.Boa disposição visual do conjunto de impactos diretos.

2. Simplicidade de elaboração.

3. Baixo custo.

Como desvantagens, considera:

1. Não identificam impactos indiretos.

2. Não consideram características espaciais dos impactos.

3. Subjetividade na atribuição da magnitude, usando valores simbólicos para expressá-la.

4. Não atendem às demais etapas do EIA.

5. Não consideram a dinâmica dos sistemas ambientais.

Segundo Tommasi (1993) o risco ambiental pode ser definido como a combinação da probabilidade de um evento-acidente, como, por exemplo, a explosão de um tanque de combustível, e por suas consequências - ferimentos, mortes, perda de equipamentos. O termo risco é usado somente quando existe a possibilidade de consequências negativas resultantes de vários fatores como: natureza do perigo, possibilidade de exposição e características da população exposta, probabilidade de ocorrência, e magnitude das exposições e consequências.

De acordo com Sánchez (2008) os riscos ambientais são classificados em três tipos:

1.Os riscos físicos, que são representados pelo ambiente de trabalho que causa danos ao meio ambiente e riscos ergonômicos ao trabalhador, através da iluminação, vibração, ruído, calor, etc. 2. Riscos químicos presentes no ambiente de trabalho sob forma de poeira, gás, vapor, fumos, névoa e líquidos.

3. Riscos biológicos representados por microrganismos presentes no ambiente de trabalho e que podem causar doenças de natureza moderada ou grave.

\section{MATERIAIS E MÉTODOS}

O município de Alagoa Nova localiza-se na unidade geoambiental do Planalto da Borborema, no estado da Paraíba, Brasil. A vegetação é típica do agreste, formada por Florestas Subcaducifólica e Caducifólica. O clima é ameno, característico do brejo de altitude. O município encontra-se inserido na Bacia Hidrográfica do Rio Mamanguape. Os principais tributários são os rios Mamanguape e Riachão, além dos riachos Ribeira e Pinga, todos de regime de escoamento intermitente. Segundo o IBGE (Instituto Brasileiro de Geografia e Estatística), dados de 2010 a população sua população é de 19.686 habitantes e a densidade populacional é de $161,03 \mathrm{hab} . / \mathrm{km}^{2}$.

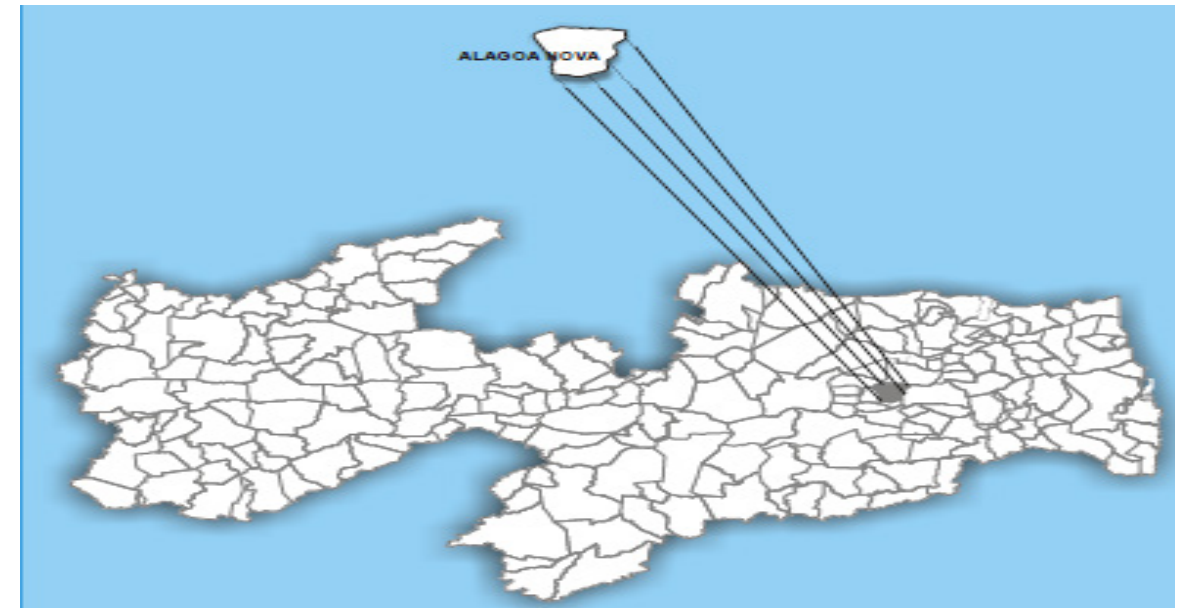

Figura 1: Localização de Alagoa Nova no estado da Paraíba. 
Fonte: Serviço Geológico do Brasil, 2005.

A análise e setorização do grau de risco de processos de instabilização de encostas, considerando o arranjo dos impactos presentes nas áreas avaliadas consistiram em vistorias técnicas realizadas nos Bairros Ivaldolândia, Conjunto Vida Nova, Mazagão e Mutirão, no período de novembro de 2011 a fevereiro de 2012, localizados no Município de Alagoa Nova, PB- para delimitação dos setores de risco.

O processo de compartimentação de setores de risco correspondeu aos critérios adotados na metodologia proposta pelo Instituto de Pesquisas Tecnológicas do Estado de São Paulo- IPT (2007) para o Ministério das Cidades, no tocante às diretrizes para erradicação de riscos em assentamentos precários sujeitos a acidentes de instabilização de encostas.

A análise de riscos e impactos ambientais consistiu das seguintes etapas:

1.Delimitação da área de estudo.

2.Identificação da tipologia dos processos geodinâmicos.

3.Mapeamento de risco.

4.Elaboração da matriz de Leopold.

\section{RESULTADOS E DISCUSSÃO}

A Figura 2 mostra a localização das áreas de risco do município destacadas em tons amarelos.

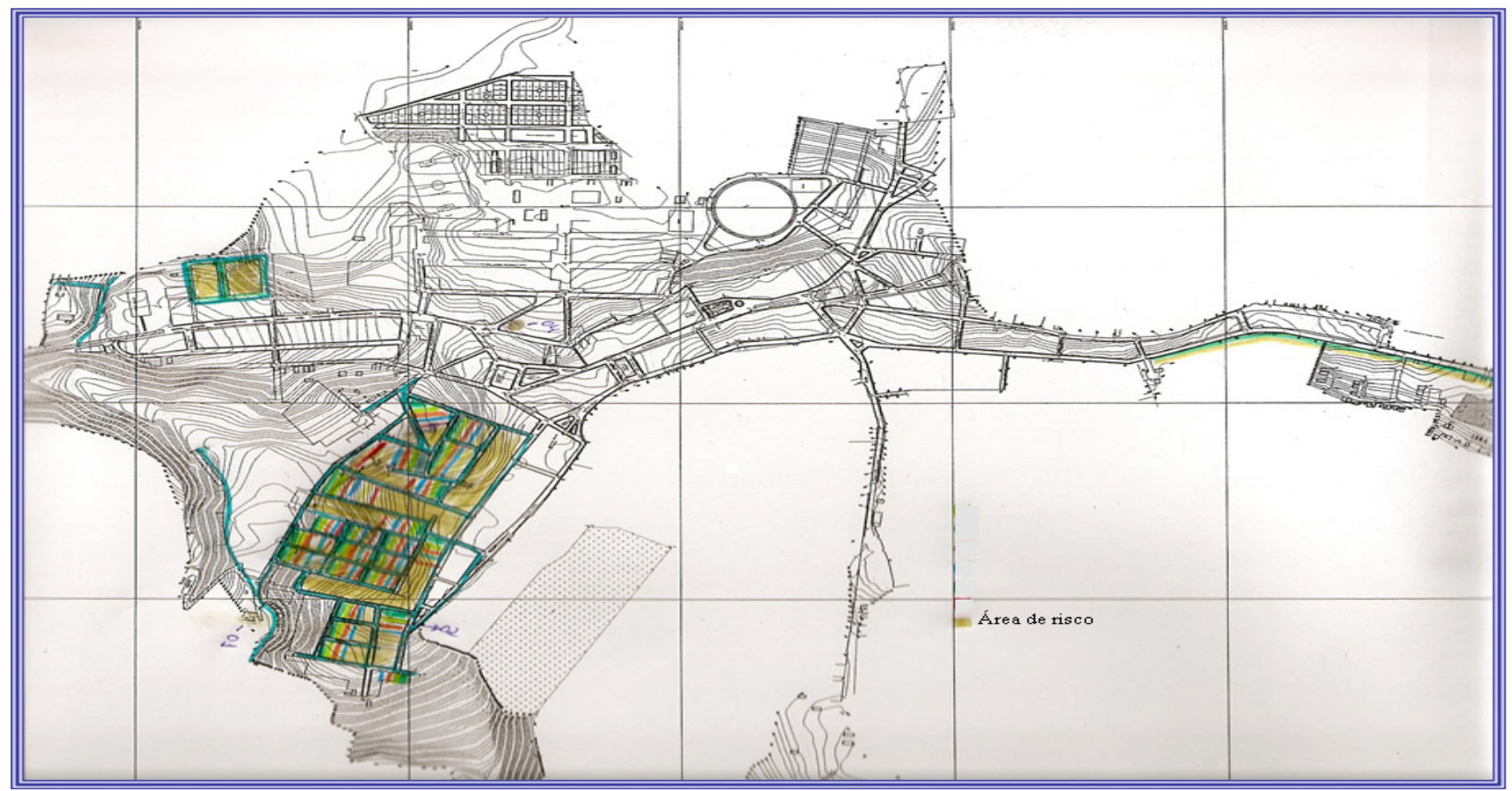

Figura 2: Localização das áreas de riscos, Alagoa Nova-PB.

Os riscos aqui tratados resume-se, em encostas, que podem atingir de forma danosa a população residente em moradias. A desordenada ocupação humana tende a modificar desfavoravelmente a suscetibilidade natural dos terrenos, dando origem aos processos de instabilização de encostas.

De acordo com o Instituto Geológico do estado de São Paulo (2008), os fatores de perigo para análise da probabilidade de ocorrência de rupturas, que deverão ser consideradas para definição do grau de perigo são as seguintes:

1.Declividade do terreno de média a alta $(>30 \%)$.

2.Presença de encostas e taludes de cortes com altura elevada $(\mathrm{H}>3,0 \mathrm{~m})$.

3.Ação desfavorável da água no terreno e existência de linhas de drenagem.

4.Presença de blocos rochosos no setor ou à montante da seção.

5.Histórico de incidentes de escorregamentos (recorrência). 
O grau de risco será analisado de acordo com a Tabela 1:

Tabela 1: Condicionantes e grau de risco

\begin{tabular}{|c|c|c|c|c|}
\hline $\begin{array}{c}\text { Condicionantes } \\
\text { naturais }\end{array}$ & $\begin{array}{l}\text { Intervenções } \\
\text { Antrópicas }\end{array}$ & $\begin{array}{l}\text { Processos do } \\
\text { meio físico }\end{array}$ & $\begin{array}{l}\text { Vulnerabilidade } \\
\text { da ocupação }\end{array}$ & $\begin{array}{c}\text { Grau de } \\
\text { risco }\end{array}$ \\
\hline $\begin{array}{l}\text { Geometria da } \\
\text { encosta }\end{array}$ & Talude de corte & $\begin{array}{c}\text { Escorregamento } \\
\text { natural }\end{array}$ & $\begin{array}{c}\text { Nível de } \\
\text { adensamento }\end{array}$ & $\begin{array}{c}\text { R1- } \\
\text { Baixo }\end{array}$ \\
\hline \multicolumn{5}{|l|}{ Declividades } \\
\hline $\begin{array}{l}\text { Baixa: } 20 \text { a } 30 \% \\
\text { Média: } 30 \text { a } 60 \%\end{array}$ & Talude de aterro & $\begin{array}{l}\text { Escorregamento } \\
\text { induzido }\end{array}$ & $\begin{array}{c}\text { Padrão } \\
\text { construtivo das } \\
\text { casas }\end{array}$ & $\begin{array}{c}\text { R2- } \\
\text { Médio }\end{array}$ \\
\hline \multicolumn{5}{|l|}{ Alta: $60 \%$} \\
\hline $\begin{array}{l}\text { Perfil geológico- } \\
\text { geotécnico }\end{array}$ & Solo exposto & $\begin{array}{l}\text { Enchente com } \\
\text { alta energia de } \\
\text { escoamento }\end{array}$ & $\begin{array}{c}\text { Consolidação } \\
\text { urbana }\end{array}$ & R3- Alto \\
\hline $\begin{array}{l}\text { Fragmentos } \\
\text { rochosos instáveis }\end{array}$ & $\begin{array}{c}\text { Coberturas } \\
\text { superficiais } \\
\text { antropogênicas }\end{array}$ & Fluxo de detritos & $\begin{array}{c}\text { Posição das } \\
\text { casas na encosta }\end{array}$ & $\begin{array}{l}\text { R4- } \\
\text { Muito } \\
\text { Alto }\end{array}$ \\
\hline
\end{tabular}

Fonte: Adaptado do IPT (2007).

Os bairros Ivaldolândia, Conjunto Vida Nova, Mazagão e Mutirão foram divididos em 16 setores. O bairro Ivaldolândia constitui os setores $(01,02,03,04)$, o Conjunto Vida Nova representam os setores $(05,06,07,08)$, o Mazagão $(09,10,11,12)$ e o Mutirão $(13,14,15,16)$. O grau de risco atribuído a cada setor é apresentado na Tabela 2.

Tabela 2: Grau de risco atribuído a cada setor

\begin{tabular}{cccc}
\hline $\begin{array}{c}\text { Setores de Risco } \\
\text { Muito Alto (R4) }\end{array}$ & $\begin{array}{c}\text { Setores de Risco Alto } \\
\text { (R3) }\end{array}$ & $\begin{array}{c}\text { Setores de Risco Médio } \\
\text { (R2) }\end{array}$ & $\begin{array}{c}\text { Setores de Risco } \\
\text { Baixo (R1) }\end{array}$ \\
\hline Setor 04 & Setor 03 & Setor 02 & Setor 01 \\
Setor 08 & Setor 07 & Setor 06 & Setor 05 \\
Setor 12 & Setor 11 & Setor 10 & Setor 09 \\
Setor 16 & Setor 15 & Setor 14 & Setor 13 \\
\hline
\end{tabular}
adotada:

A seguir são descritas as características gerais dos setores avaliados segundo a metodologia

Setores de risco muito alto (R4): quando o talude ou a encosta se enquadrar numa declividade entre média e alta, portanto, rampas com declividade superior a 30\%. Moradias situadas na meia encosta e na base da encosta e inexistência de um sistema de drenagem, solos muito acidentados.

Setores de risco alto (R3): terreno com trincas, rachaduras e estruturas de contenção precárias. Terrenos constituídos por materiais instáveis, material transportado por processos erosivos.

Setores de risco médio (R2): qualidade das construções/habitações precárias, inexistência de esgotamento sanitário.

Setores de risco baixo (R1): setor com baixa a média taxa de ocupação, terrenos apresentam 
proteção superficial, taludes com declividade inferior a 5\%.

Durante essas inspeções técnicas de campo, foram obtidas várias fotografias, Figura 3, visando ilustrar a descrição de características dos terrenos e condições atuais de adensamento urbano e vulne-
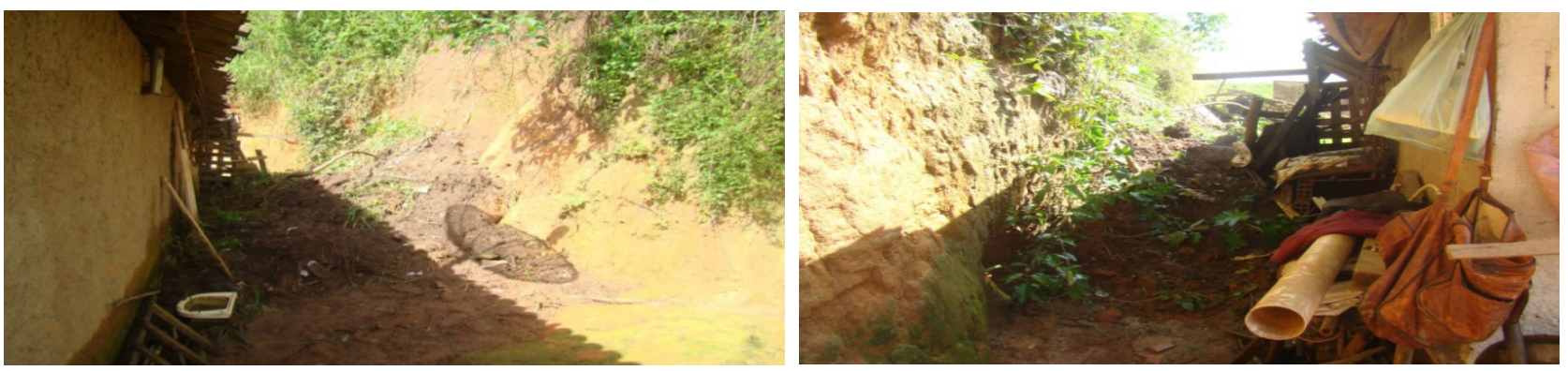

rabilidade das ocupações.
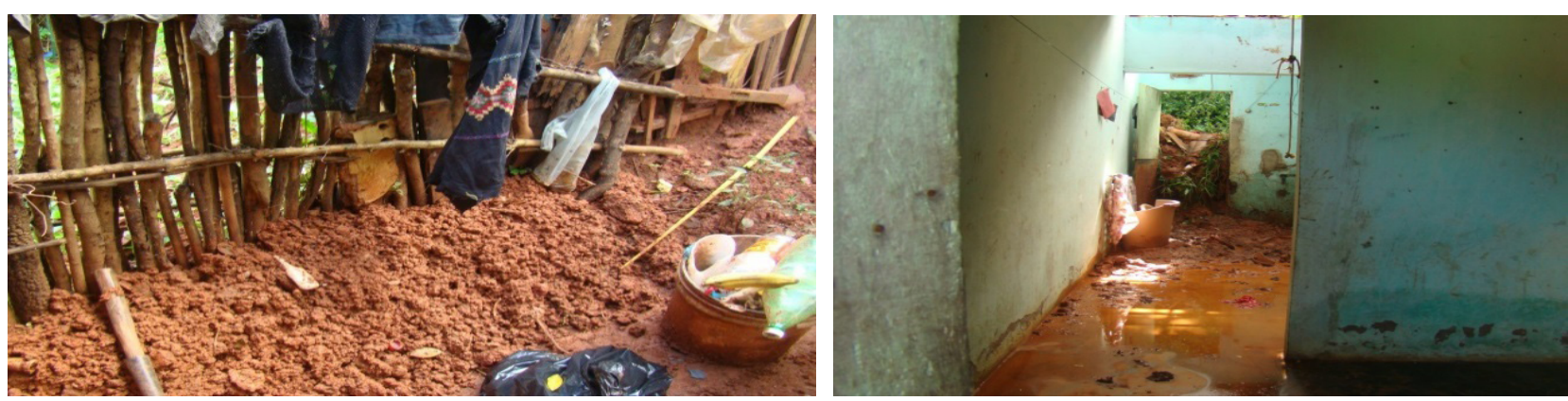

Setor 01: Aspecto das condições de moradia (R3)

Setor 13: Condições insalubres (R2).

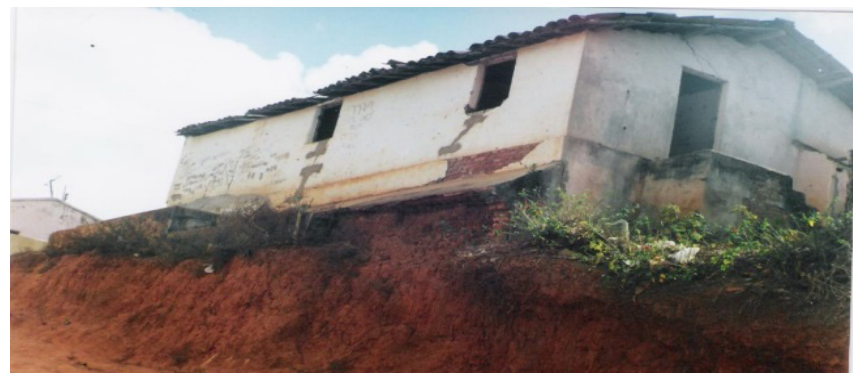

Setor 01: Detalhe de inclinação de talude (R4)

Setor 01: Moradias em períodos chuvosos (R3)

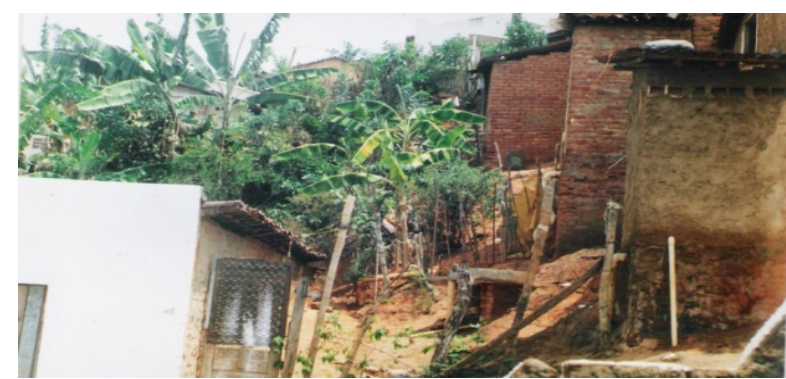

Setor 08: Detalhe da elevada inclinação do talude (R4).

Setor 09: Presença de vegetação nas encostas (R1)

Figura 3. Características dos terrenos e condições atuais de adensamento urbano e vulnerabilidade das ocupações no munícipio de Alagoa Nova-PB.

Fonte: Autor (2012).

De acordo com o exposto verifica-se que a posição das moradias em relação à inclinação dos taludes gera riscos que podem ser classificados em risco baixo (R1), risco médio (R2), risco alto (R3) ou risco muito alto (R4) para as moradias existentes, e que a geometria das encostas é favorável à ocorrência de escorregamento em períodos chuvosos, juntamente com o padrão construtivo das casas contribuindo para um ambiente insalubre e com riscos de acidentes.

A Figura 4 apresenta a localização dos conjuntos habitacionais

A quantificação dos impactos e aspectos ambientais deu-se por meio da matriz de Leopold. Ressalta-se que o valor total para cada aspecto é definido através de estimativa de técnicos e engenheiros da Defesa Civil que avalia os aspectos e impactos ambientais com maior ou menor significância.

A Tabela 3 apresenta valorização dos impactos utilizados na identificação e classificação dos aspectos e impactos ambientais decorrentes da implantação de conjuntos habitacionais no município 


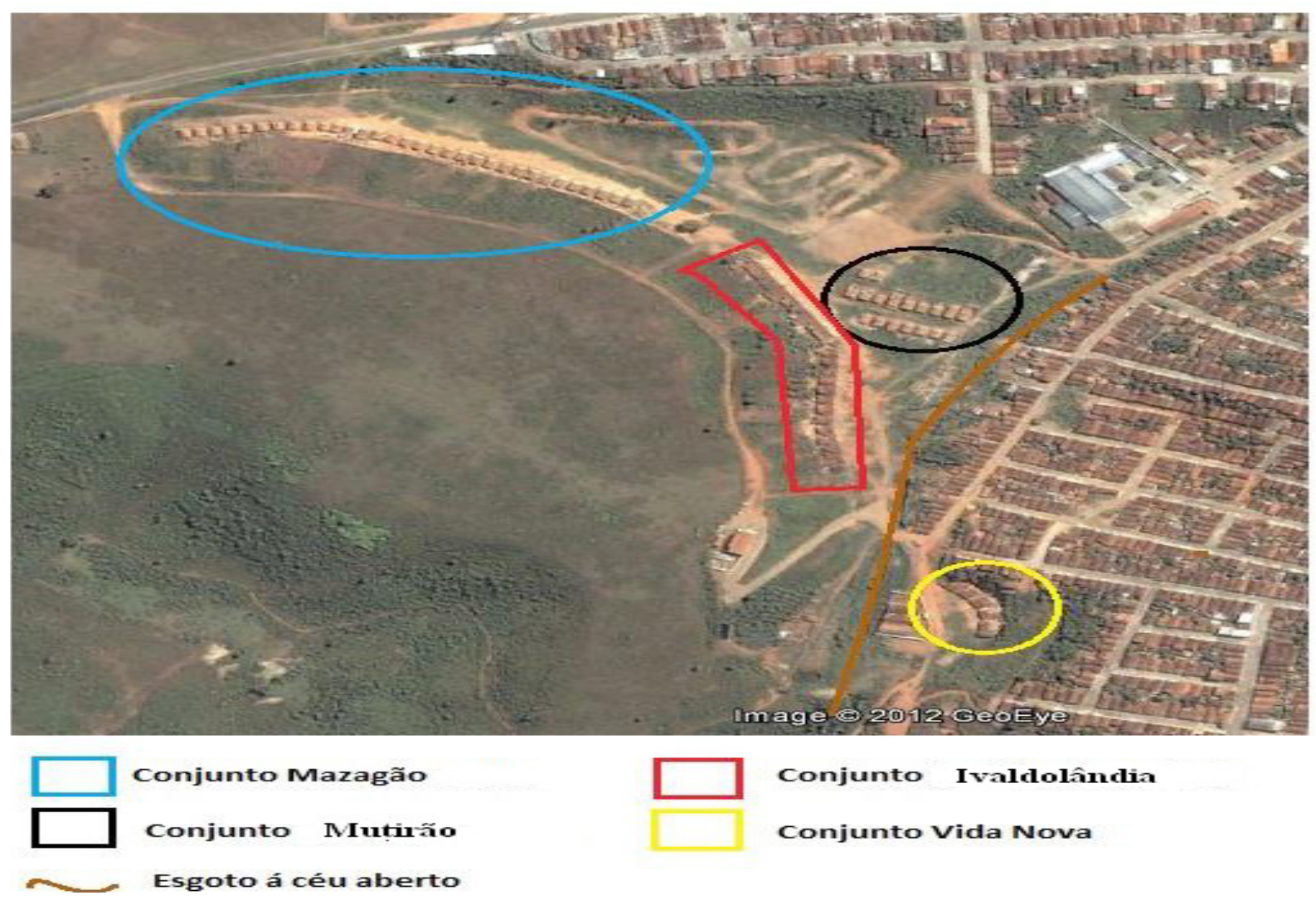

de Alagoa Nova, PB. Impacto Total: $\mathrm{IT}=\mathrm{Ca} .(\mathrm{I}+\mathrm{Co}+\mathrm{D}+\mathrm{R})$

Figura 4: Localização dos Conjuntos Habitacionais em Alagoa Nova, PB.

Fonte: Google Earth modificada (2013).

Tabela 3: Valorização do Impacto

\begin{tabular}{|l|l|l|l}
\hline \multicolumn{4}{|c}{ Valorização do Impacto } \\
\hline Caráter (Ca) & Positivo (1) & $\begin{array}{l}\text { Neutro } \\
(0)\end{array}$ & Negativo (-1) \\
\hline Importância (I) & Alta (3) & $\begin{array}{l}\text { Média } \\
(2)\end{array}$ & Baixa (1) \\
\hline Cobertura (Co) & Regional (3) & Média(2) & Baixa(1) \\
\hline & $\begin{array}{l}\text { Permanente } \\
\text { (3) }\end{array}$ & Local(2) & Pontual (1) \\
\hline Duração (D) & Irreversível(3) & Parcial(2) & Reversível(1) \\
\hline Reversibilidade(R)
\end{tabular}




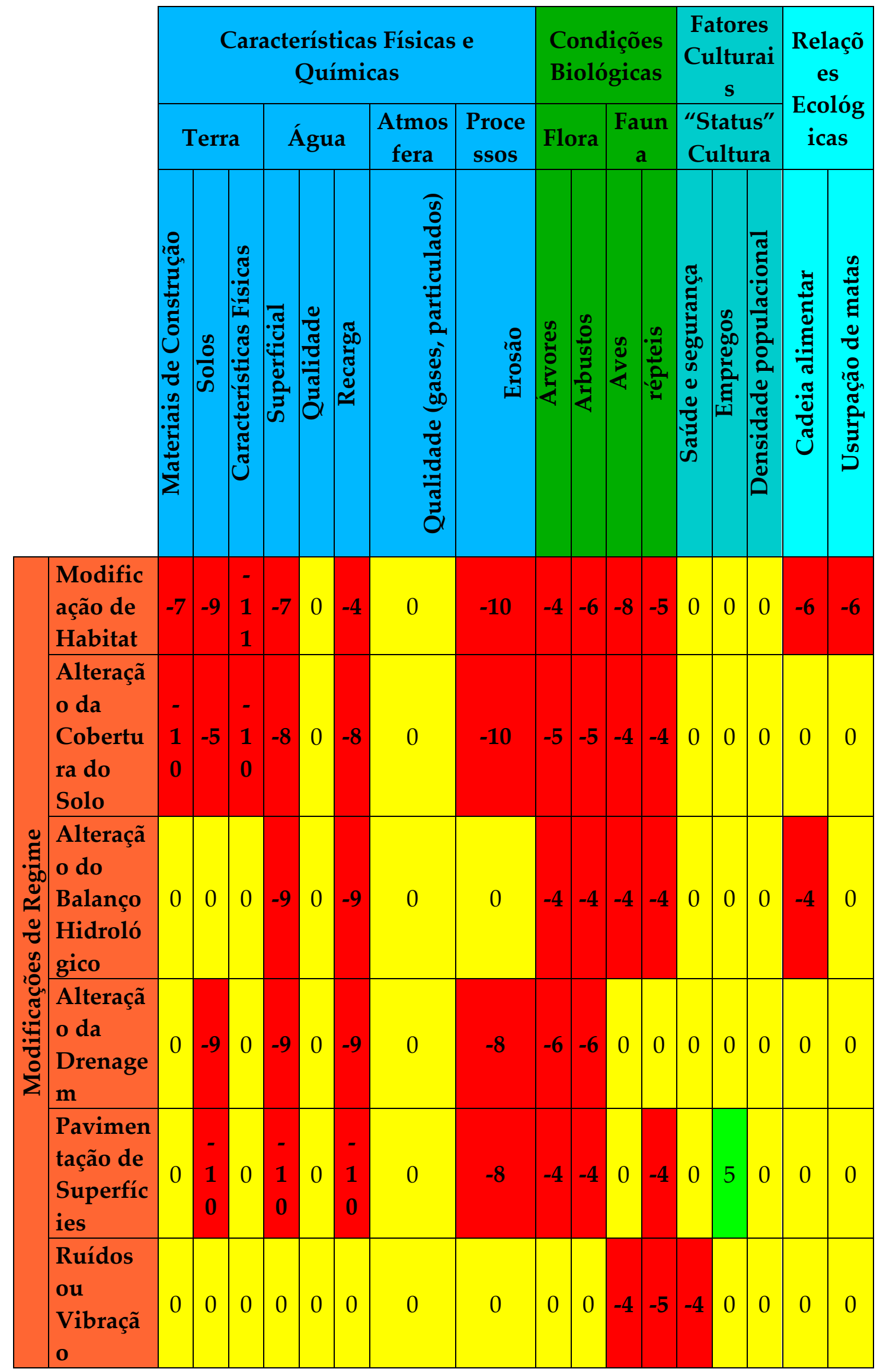




\begin{tabular}{|c|c|c|c|c|c|c|c|c|c|c|c|c|c|c|c|c|c|c|}
\hline \multirow{6}{*}{ 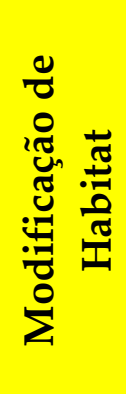 } & Caráter (Ca) & -1 & -1 & -1 & -1 & 0 & -1 & 0 & -1 & -1 & -1 & -1 & -1 & 0 & 0 & 0 & -1 & -1 \\
\hline & Importância (I) & 2 & 2 & 3 & 1 & 0 & 1 & U & 3 & 1 & 3 & 1 & 2 & 0 & 0 & 0 & 2 & 2 \\
\hline & Cobertura (Co) & 2 & 2 & 2 & 1 & 0 & 1 & 0 & 2 & 1 & 1 & 1 & 1 & 0 & 0 & 0 & 2 & 2 \\
\hline & Duração (D) & 2 & 3 & 3 & 3 & 0 & 1 & 0 & 3 & 1 & 1 & 3 & 1 & 0 & 0 & 0 & 1 & 1 \\
\hline & $\begin{array}{c}\text { Reversibilidade } \\
(\mathrm{R})\end{array}$ & 1 & 2 & 3 & 2 & 0 & 1 & 0 & 2 & 1 & 1 & 3 & 1 & 0 & 0 & 0 & 1 & 1 \\
\hline & Total & -7 & -9 & -11 & -7 & 0 & -4 & & -10 & -4 & -6 & -8 & -5 & 0 & 0 & 0 & -6 & -6 \\
\hline
\end{tabular}

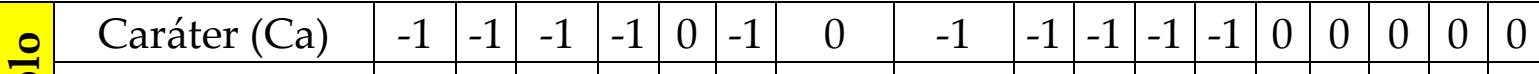

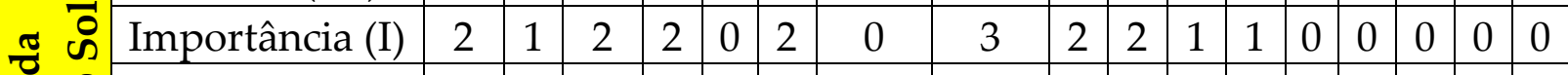

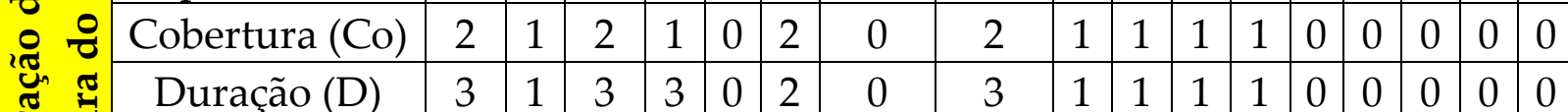
焉 (R) $\begin{array}{llllllllllllllllllll}3 & 2 & 3 & 2 & 0 & 2 & 0 & 2 & 1 & 1 & 1 & 1 & 0 & 0 & 0 & 0 & 0\end{array}$ Total \begin{tabular}{ll|l|l|l|l|l|l|l|l|l|l|l|l|l|l|l|}
-10 & -5 & -10 & -8 & 0 & -8 & 0 & -10 & -5 & -5 & -4 & -4 & 0 & 0 & 0 & 0 & 0 \\
\hline
\end{tabular}

\begin{tabular}{|c|c|c|c|c|c|c|c|c|c|c|c|c|c|c|c|c|c|c|}
\hline & \multicolumn{17}{|c|}{-1} & 0 \\
\hline & Importância (I) & 0 & 0 & 0 & 3 & 0 & 3 & & & 1 & 1 & 1 & 1 & 0 & 0 & 0 & 1 & 0 \\
\hline & Cobertura (Co) & 0 & 0 & 0 & 2 & 0 & 2 & 0 & & 1 & 1 & 1 & 1 & 0 & 0 & 0 & 1 & 0 \\
\hline & Duração (D) & 0 & 0 & 0 & 2 & 0 & 2 & 0 & & 1 & 1 & 1 & 1 & 0 & 0 & 0 & 1 & 0 \\
\hline & $\begin{array}{l}\text { Reversibilidade } \\
\text { (R) }\end{array}$ & 0 & 0 & 0 & 2 & 0 & 2 & 0 & 0 & 1 & 1 & 1 & 1 & 0 & 0 & 0 & 1 & 0 \\
\hline & Total & $\mathbf{0}$ & 0 & 0 & -9 & 0 & -9 & $\mathbf{0}$ & & -4 & -4 & -4 & -4 & 0 & 0 & 0 & -4 & 0 \\
\hline
\end{tabular}

\begin{tabular}{|c|c|c|c|c|c|c|c|c|c|c|c|c|c|c|c|c|c|c|}
\hline \multirow{6}{*}{ 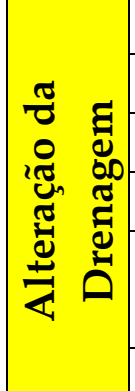 } & Cará & 0 & -1 & 0 & -1 & 0 & -1 & & -1 & -1 & -1 & 0 & 0 & 0 & 0 & 0 & & 0 \\
\hline & Importância (I) & 0 & 3 & 0 & 3 & 0 & 3 & & 2 & 2 & 2 & 0 & 0 & 0 & 0 & 0 & 0 & 0 \\
\hline & Cobertura (Co) & 0 & 2 & 0 & 2 & 0 & 2 & & 2 & 2 & 2 & 0 & 0 & 0 & 0 & 0 & 0 & 0 \\
\hline & Duração (D) & 0 & 2 & & & & 2 & & & 1 & & & & 0 & 0 & 0 & 0 & 0 \\
\hline & $\begin{array}{l}\text { Reversibilidade } \\
\text { (R) }\end{array}$ & 0 & 2 & 0 & ? & & 2 & & ? & 1 & & & O & 0 & 0 & 0 & & 0 \\
\hline & Total & 0 & -9 & 0 & & 0 & S & & -0 & -6 & & 0 & & & 0 & 0 & & 0 \\
\hline
\end{tabular}

\begin{tabular}{|c|c|c|c|c|c|c|c|c|c|c|c|c|c|c|c|c|c|c|}
\hline \multirow{6}{*}{ 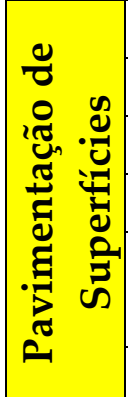 } & Caráter (Ca) & 0 & -1 & 0 & -1 & 0 & -1 & 0 & -1 & -1 & & 0 & -1 & & & 0 & & \\
\hline & Importância (I) & & 3 & 0 & 3 & C & 2 & & & 1 & & 0 & 1 & 0 & 1 & 0 & & 0 \\
\hline & Cobert & 0 & 2 & 0 & 2 & 0 & 2 & & & 1 & 1 & 0 & 1 & 0 & 1 & 0 & J & 0 \\
\hline & Duração (D) & 0 & 2 & 0 & 3 & 0 & 3 & & 3 & 1 & 1 & 0 & 1 & 0 & 2 & 0 & ) & 0 \\
\hline & $\begin{array}{l}\text { Reversibilidade } \\
\text { (R) }\end{array}$ & 0 & 3 & 0 & 2 & 0 & 3 & 0 & 1 & 1 & 1 & 0 & 1 & 0 & 1 & 0 & ) & 0 \\
\hline & Total & 0 & -10 & 0 & -10 & & -10 & & -8 & -4 & & 0 & & 0 & 5 & 0 & & 0 \\
\hline
\end{tabular}




\begin{tabular}{|c|c|c|c|c|c|c|c|c|c|c|c|c|c|c|c|c|c|c|}
\hline \multirow{6}{*}{ 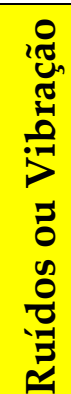 } & Caráter $(\mathrm{Ca})$ & 0 & 0 & 0 & 0 & 0 & 0 & 0 & 0 & 0 & 0 & -1 & -1 & -1 & 0 & 0 & 0 & 0 \\
\hline & Importância (I) & 0 & 0 & 0 & 0 & 0 & 0 & 0 & 0 & 0 & 0 & 1 & 2 & 1 & 0 & 0 & 0 & 0 \\
\hline & Cobertura (Co) & 0 & 0 & 0 & 0 & 0 & 0 & 0 & 0 & 0 & 0 & 1 & 1 & 1 & 0 & 0 & 0 & 0 \\
\hline & Duração (D) & 0 & 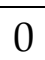 & 0 & 0 & 0 & 0 & 0 & 0 & 0 & 0 & 1 & 1 & 1 & 0 & 0 & 0 & 0 \\
\hline & $\begin{array}{c}\text { Reversibilidade } \\
\text { (R) }\end{array}$ & 0 & 0 & 0 & 0 & 0 & 0 & 0 & 0 & 0 & 0 & 1 & 1 & 1 & 0 & 0 & 0 & 0 \\
\hline & Total & 0 & 0 & 0 & 0 & 0 & 0 & 0 & 0 & 0 & 0 & -4 & -5 & -4 & 0 & 0 & 0 & 0 \\
\hline
\end{tabular}

A partir da quantificação das avaliações escalares incluídas na matriz de Leopold apresentada, foram diagnosticados impactos negativos nas características físicas, químicas, biológicas e nas relações ecológicas oriundas da implantação dos conjuntos habitacionais do referente município.

Os principais impactos negativos que afetam as características físicas do município de acordo com a metodologia empregada são: erosão e instabilidade das margens, assoreamento do curso d'água, compactação do solo, alteração da topografia, impermeabilização do solo, diminuição da infiltração e aumento do escoamento superficial. No meio biológico tem-se a diminuição ou perda de biodiversidade e alteração do ecossistema natural. Um dos impactos positivos no meio antrópico são áreas para habitação; e os negativos são os riscos de desabamento, aumento das enchentes e inundações, aumento dos custos com utilidades públicas, danos à população e diminuição da qualidade estética e paisagística.

A implantação dos conjuntos habitacionais no município de Alagoa Nova, PB de forma desordenada originou a necessidade de novos serviços ou alterações nos existentes nas seguintes áreas: planejamento urbano, arborização, sistema de esgotamento sanitário, segurança e saúde pública.

Umas das medidas mitigadoras utilizadas para estabilização de encostas é o uso de muros de contenção (muros de arrimo). Esses são estruturas construídas para suportar uma massa de solo permanentemente. Muros de contenção também são usados para prevenir ou minimizar a erosão regressiva pela correnteza de rios ou para retardar deslizamentos muito lentos. Eles não podem, no entanto, ser usados para impedir deslizamentos. Vários tipos básicos de estruturas de contenção são montagem de madeira, em forma de fogueira, silo de aço, pilha, balanço ou console, pilha em folhas, malha plástica e terra reforçada. Cada um desses tipos tem vantagens em determinadas situações, mas o custo é geralmente o que determina o tipo aprovado (HIGHLAND and BOBROWSKY, 2008).

A presença de vegetação reduz a erosão da superfície que pode em certas condições conduzir a deslizamentos, a plantação de arbustos aumenta a cobertura vegetal e gera um sistema mais forte de raízes, que por sua vez, irão reforçar a estabilidade de taludes. Se não forem controlados, a erosão superficial e deslizamentos pequenos e rasos em encostas podem levar a problemas maiores de impossível controle. A erosão em grande escala requer aplicação de tecnologia em engenharia para correção e controle. A implementação de um programa de reflorestamento para o controle da drenagem da água de superfície, remoção das saliências do barranco, redução dos ângulos de inclinação e assentamentos, tudo deve ser feito antes do começo da semeadura (HIGHLAND and BOBROWSKY, 2008).

\section{CONCLUSÃO}

A matriz de impactos torna-se relevante para estudos de impactos ambientais à medida que leva em conta todos os componentes diretamente e indiretamente afetados pela implantação do projeto em todas as suas fases.

De acordo com o exposto verifica-se que a posição das moradias em relação à inclinação dos taludes gera risco para as moradias existentes, e que a geometria das encostas é favorável à ocorrência de escorregamento em períodos chuvosos, juntamente com o padrão construtivo das casas que contribuem para um ambiente insalubre e com riscos de acidentes.

Um dos problemas observados é a falta de controle e infraestrutura no processo de urbanização. As consequências dos deslizamentos poderiam ser menores se não houvesse as ocupações desordenadas 
em áreas de risco, sendo necessária a elaboração de medidas de prevenção e segurança para a população.

No projeto avaliado torna-se necessário definir critérios ambientais adequados, que sirvam para a criação de faixas de proteção com restrição de uso e ocupação ao longo dos cursos d'água, evitando o máximo a impermeabilização dessas áreas, de modo a favorecer a infiltração, se necessário, fazer a utilização de pavimentos permeáveis e evitar alterações drásticas da topografia, respeitando os afastamentos mínimos estabelecidos junto às encostas.

\section{REFERÊNCIAS}

BRASIL. Ministério das Cidades. Instituto de Pesquisas Tecnológicas (IPT). Mapeamento de riscos em encostas e margens de rios. Brasília: Ministério das Cidades; Instituto de Pesquisas Tecnológicas (IPT), 2007. 176 p.

BRASIL. Ministério da Integração Nacional. Política Nacional de Defesa Civil. Brasília: Secretaria Nacional de Defesa Civil, 2007. 82p.

CONSELHO NACIONAL DO MEIO AMBIENTE. Resoluções CONAMA 1986-1991. Brasília: IBAMA, 1992.

FOGLIATTI, MARIA CRISTINA. Avaliação de impactos ambientais: aplicação aos sistemas de transporte. Rio de Janeiro: Interciência, 2004.

HIGHLAND, L.M.; BOBROWSKY, PETER. The landslide handbook - A guide to understanding landslides: Reston, Virginia, U.S. Geological Survey Circular 1325, 2008. 129p.

INSTITUTO BRASILEIRO DE GEOGRAFIA E ESTATÍSTCA (IBGE). Censo Demográfico 2010.

INSTITUTO DE PESQUISAS TECNOLÓGICAS DO ESTADO DE SÃO PAULO (IPT). Análise de riscos geológicos e geotécnicos dos bairros Cota 95/100, 200 e 400 no município de Cubatão, SP. Relatório Técnico No $97765-205$ - i. 2007.

INSTITUTO GEOLÓGICO. Mapeamento das áreas de risco a escorregamentos e inundações no município de São Luiz do Paraitinga. Termo de Cooperação Técnica IGCEDEC de 01/11/2007. São Paulo: Relatório Técnico. vol.1, 2008.

LEOPOLD, L.B.; CLARKE, F.E.; HANSHAW, B.B.; BALSLEY, J.R. A procedure for evaluating environmental impact. Washington, D.C.: US Geological Survey, 1971. (Circular 645).

MOREIRA, I.V.D. Origem e Síntese dos Principais Métodos de Avaliação de Impacto Ambiental (AIA). In: MANUAL DE AVALIAÇÃO DE IMPACTOS AMBIENTAIS. Curitiba: SEMA/IAP/GTZ, 1995.

PIMENTEL, G.; PIRES, S.H. Metodologias de avaliação de impacto ambiental: Aplicações e seus limites. Rio de Janeiro, Revista de Administração Pública, 26(1), p.56-68. jan/mar, 1992.

SILVA, A.M. Estudo de impacto ambiental: planejamento ecológico. João Pessoa: SUDEMA, 1989.

SOUZA, E.B. Desenvolvimento urbano na década de 90. In: IPEA/IPLAN. Para a década de 90 prioridades e perspectivas de políticas públicas. Brasília: IPEA/IPLAN, 1999.

SÁNCHEZ, LUIS ENRIQUE. Avaliação de Impacto Ambiental: conceitos e métodos. São Paulo: Oficina de textos, 2008.

TOMMASI, LUIZ ROBERTO. Estudo de Impacto Ambiental. São Paulo: CETESB: Terragraph Artes e Informática, 1993. 